\title{
Cerebral microembolism in patients with stroke or transient ischaemic attack as a risk factor for early recurrence
}

\author{
L Valton, V Larrue, A Pavy Le Traon, G Géraud
}

\begin{abstract}
The incidence of early recurrence in 32 patients who had had a transient ischaemic attack or stroke in the anterior circulation was studied. Patients with a potential cardiac source of embolism were excluded from the study. All patients had transcranial Doppler (TCD) monitoring of the symptomatic middle cerebral artery for microembolic signal detection within seven days from the onset of symptoms. Four patients had early recurrence during a mean follow up of 15 (SD11) days. All early recurrences occurred in the same arterial territory as the initial ischaemic event. Three of the four patients with early recurrence had prior microembolic signals. The incidence of early recurrence was $50 \%(3 / 6)$ in patients with microembolic signals and $3.8 \%(1 / 26)$ in patients without microembolic signals $(P=0.02)$. The findings suggest that TCD monitoring of patients with recent cerebral ischaemia of presumed arterial origin allows recognition of a subset of patients at high risk for early recurrence.
\end{abstract}

(F Neurol Neurosurg Psychiatry 1997;63:784-787)

Keywords: transcranial Doppler ultrasound; stroke; cerebral embolism

Service de Neurologie, Hôpital de Rangueil, CHU de Toulouse, France

L Valton

V Larrue

A Pavy Le Traon

G Géraud

Correspondence to: Dr V Larrue, Service de Neurologie, Hôpital de Rangueil, CHU de Toulouse, 31403 Toulouse Cedex 04,

France.

Received 14 February 1997 and in revised form 24 April 1997

Accepted 4 June 1997
Patients with symptomatic high grade carotid stenosis or thick aortic arch atheroma are at risk for recurrence of stroke. ${ }^{1-3}$ However, not all the patients with such arterial lesions develop recurrence. Methods that might help to select patients at highest risk for recurrence would be useful for therapeutic decisions.

Asymptomatic microembolic signals can be demonstrated in patients with carotid stenosis or aortic arch atheroma using transcranial Doppler (TCD) monitoring of the middle cerebral artery. ${ }^{4-7}$ In patients with carotid stenosis, microembolism has been related to the degree of carotid narrowing ${ }^{8}$ and to the ulcerated appearance of the plaque. ${ }^{910}$ However, the prognostic relevance of microembolic signals remains uncertain. The purpose of our study was to estimate the risk of early ischaemic recurrence in patients with cerebral ischaemia of presumed arterial origin, in whom TCD monitoring demonstrated microembolic signals.

\section{Methods}

We followed up 32 patients who were under medical treatment after transient ischaemic attack or stroke in the anterior circulation. All patients were selected from a series of 41 consecutive patients who were monitored for microembolic signal detection within seven days from the onset of symptoms. Because we wanted to focus on the risk of recurrence in patients with cerebral ischaemia of presumed arterial origin, we excluded the nine patients with a potential cardiac source of emboli (atrial fibrillation, intracardiac thrombus, recent myocardial infarction, valvar disease, or prosthetic valves), as detected by history, ECG, and echocardiography. The mean age of the 32 selected patients (25 men and seven women) was 67 (range 32 to 96) years. Twelve patients presented with a transient ischaemic attack and 20 with ischaemic stroke. All patients underwent carotid duplex and TCD ultrasonography. Carotid angiography was performed in 18 patients and magnetic resonance angiography in two. Carotid stenoses were graded using the North American Symptomatic Carotid Endarterectomy Trial criteria $^{11}$ in patients who underwent angiography and standard ultrasonographic criteria (peak and telediastolic velocities and spectral broadening) in the others. Intracranial carotid stenosis, proximal common carotid stenosis, and carotid dissection were diagnosed by angiography after duplex and TCD screening. Atheroma in the proximal aorta and aortic dissection were diagnosed by transesophageal echocardiography using a biplanar or multiplanar $5 \mathrm{MHz}$ probe. A potential arterial source of emboli was defined as carotid stenosis $\geqslant 70 \%$ (extracranial in 10 , intracranial in one, proximal common carotid in one), carotid dissection (one patient), plaque $\geqslant 5 \mathrm{~mm}$ in the ascending or horizontal aorta (five patients), or aortic dissection (one patient). All patients were initially treated 
with heparin and all but two were also treated with aspirin.

Unilateral 20 minute TCD monitoring of the middle cerebral artery was performed on the symptomatic side. Studies with TCD were performed according to previously described methods $^{10}$ using a Pioneer 2020 (EME Nicolet). Briefly, after location of the artery, a 2 $\mathrm{MHz}$ transducer was attached with an elastic head strap. The depth was chosen from 45 to $50 \mathrm{~mm}$ to obtain maximum insonation of the middle cerebral artery. Then, gain and sample volume were reduced (to $10 \mathrm{~mm}$ for the sample volume) and the time window overlap was increased to $72 \%$ to obtain better detection of microembolic signals. ${ }^{12} 13$ The audible Doppler shift and the fast Fourier transformed spectra were continuously observed by an experienced investigator who noted all events that could be sources of artifacts. All monitorings were recorded on digital audiotapes and were analysed off line by two independent observers who were blinded to the clinical data. The diagnosis of microembolic signals was done in agreement with international recommendations: unidirectional, within the blood flow velocity spectrum, short duration $(<0.15$ and $<0.3 \mathrm{~s}$ for systolic and diastolic signals respectively), high intensity ( $\geqslant 6 \mathrm{~dB}$ ) signals, occurring randomly within the cardiac cycle, accompanied by a characteristic sound, and without any simultaneous detectable source of artifact. ${ }^{14}$ The $\mathrm{K}$ index for interobserver agreement in the diagnosis of microembolic signals using these criteria was 0.895 . In cases of disagreement, the signal was categorised as an artifact.

Duration of follow up was measured from the time of admission to hospital in our department of neurology. This was done because four patients had early carotid endarterectomy after their ischaemic cerebral event. Another patient had prompt surgical repair of aortic dissection. Thus for the purpose of our study, early recurrence was defined as either ischaemic stroke or transient ischaemic attack that occurred before discharge, carotid endarterectomy, or aortic surgery and was diagnosed during admission to hospital in our department by the attending neurologist. In patients with previous stroke, recurrence was defined as sudden clinical deterioration with a decrease of at least two points on the Scandinavian stroke scale ${ }^{15}$ due to either worsening of the initial deficit or a new focal deficit. Haemorrhagic transformations and brain oedema were excluded by CT.

Statistical analysis was performed using $\chi^{2}$ statistics with continuity correction for categorical variables and Student's $t$ test for
Table 1 Characteristics of patients at entry

\begin{tabular}{|c|c|c|c|c|}
\hline Characteristics & \multicolumn{2}{|c|}{ Without MES } & \multicolumn{2}{|c|}{ With MES } \\
\hline No of patients & \multicolumn{2}{|l|}{26} & \multicolumn{2}{|l|}{6} \\
\hline Age $(\mathrm{y}$, mean $(\mathrm{SD}))$ & \multicolumn{2}{|c|}{$67.5(13)$} & \multicolumn{2}{|c|}{$67.5(6)$} \\
\hline Male (n (\%)) & 22 & $(85)$ & 3 & (50) \\
\hline Hypertension (n (\%)) & 13 & $(50)$ & 4 & (67) \\
\hline Diabetes (n (\%)) & 7 & (27) & 2 & (33) \\
\hline Smoking (n (\%)) & 15 & $(58)$ & 2 & (33) \\
\hline Coronary heart disease (n (\%)) & 14 & (54) & 2 & (33) \\
\hline Dyslipidaemia (n (\%)) & 8 & $(31)$ & 2 & (33) \\
\hline Carotid stenosis $\geqslant 70 \%(\mathrm{n}(\%))$ & 8 & (1) & 4 & (67) \\
\hline Carotid dissection (n (\%)) & 1 & (4) & 0 & $(0)$ \\
\hline $\begin{array}{l}\text { Aortic arch atheroma } \geqslant 5 \mathrm{~mm} \\
\quad(\mathrm{n}(\%))\end{array}$ & 4 & (16) & 1 & (17) \\
\hline Aortic dissection (n (\%)) & 0 & (0) & 1 & (17) \\
\hline
\end{tabular}

MES=microembolic signals.

continuous variables. Significance was set at $\mathrm{P}<0.05$.

\section{Results}

Table 1 shows the characteristics of the patients at entry. Six patients had microembolic signals. Five patients with microembolic signals (83\%) and 13 patients without microembolic signals $(50 \%)$ had at least one potential arterial source of embolism. The difference was not significant $(\mathrm{P}=0.3)$.

The mean duration of follow up was 15 (SD 11) days. Early recurrence occurred after TCD monitoring in four patients and comprised two strokes and two transient ischaemic attacks. All occurred in the same arterial territory as the initial ischaemic event. Table 2 shows the characteristics of the patients with early recurrence. Laboratory examinations found a potential arterial source of emboli in three patients. The fourth one (patient 2) died a few days after the ischaemic recurrence. Pathological examination demonstrated atherosclerotic plaques on both the left anterior cerebral artery and the left middle cerebral artery, with a superimposed recent occlusive thrombus on the anterior cerebral artery lesion. No heart disease was found.

Early recurrence occurred in three patients with previous microembolic signals. Thus the incidence of early recurrence was $50 \%$ in patients with microembolic signals and $3.8 \%$ in patients without microembolic signals $(\mathrm{P}=0.02)$. The duration of follow up was not different between patients with microembolic signals and those without (16 (SD 12) v 14 (SD 11) days, $\mathrm{P}=0.53$ ). Among patients with microembolic signals, there was a nonsignificant trend toward higher individual rates of microembolic signal in patients with early recurrence (3, 9, and $33 v 3,6$, and 9 per hour).

Table 2 Clinical and transcranial Doppler monitoring features of the four patients with early recurrence

\begin{tabular}{llllllll}
\hline Patient & Sex & Age & Initial event & Source of emboli & $\begin{array}{l}\text { Microembolic } \\
\text { signals/h }\end{array}$ & $\begin{array}{l}\text { Duration of follow } \\
\text { up (days) }\end{array}$ & $\begin{array}{l}\text { Ischaemic } \\
\text { recurrence }\end{array}$ \\
\hline 1 & F & 45 & R MCA TIA & Aortic dissection & 3 & 3 & R MCA TIA \\
2 & F & 61 & L ACA stroke & None & 0 & 8 & L MCA stroke \\
3 & M & 77 & R MCA reversible stroke & R ICA 90 \% stenosis & 9 & 20 & R MCA stroke \\
4 & F & 75 & L MCA reversible stroke & L CCA 80\% stenosis & 33 & 5 & L MCA TIA \\
\hline
\end{tabular}

$\mathrm{ACA}=$ anterior cerebral artery; $\mathrm{CCA}=$ common carotid artery; $\mathrm{ICA}=$ internal carotid artery; $\mathrm{MCA}=$ middle cerebral artery; $\mathrm{R}=$ right; $\mathrm{L}=$ left; TIA = transient ischaemic attack. The duration of follow up is the time between initial event and ischaemic recurrence. 


\section{Discussion}

To our knowledge, only two previous studies have analysed the relation of microembolism to the risk of subsequent stroke. Siebler et $a l^{16}$ reported increased risk of either stroke or transient ischaemic attack in patients with asymptomatic carotid stenosis and microembolic signals. Nabavi et $a l^{17}$ found, in six patients with cardiac assist devices, a positive predictive value of microembolic signal for ischaemic clinical events of $75 \%$. Both studies included patients who were initially asymptomatic. Our result on symptomatic patients showed that microembolism in the symptomatic arterial territory was associated with increased risk of early recurrence. The incidence of early recurrence in patients with microembolic signals was as high as $50 \%$. Moreover, pathological examination of the one patient without microembolic signals who developed early recurrence showed cerebral atherosclerosis with recent superimposed thrombus but failed to disclose any source of cerebral embolism. Hence, among patients with a potential arterial source of embolism, all those who had an early recurrence had prior microembolic signals.

We used a single 20 minute recording. Repeated recording might have resulted in a higher detection rate of microembolic signals. ${ }^{6}$ Nevertheless, the incidence of microembolic signals in the present study $(19 \%)$ was of the same order of magnitude as those previously reported on similar patients. Thus in five published series of patients with recent cerebral ischemia, the incidence of microembolic signals ranged from 9.3 to $29 \% .^{18-22}$

Reported risk for early recurrent stroke varies from $1.2 \%$ to $9 \% .^{23}$ The apparently high number of early recurrences in our study may be explained by the fact that, to diagnose early recurrence, we took into account either stroke or transient ischaemic attack, whereas only strokes were considered in previous studies. ${ }^{23}$

Some previous reports suggest that microembolic signals can disappear after initiation of antithrombotic treatment. ${ }^{64}{ }^{25}$ In our study all patients were already on antithrombotic medication at the time of TCD monitoring. Therefore, we cannot exclude the possibility that we have isolated a subgroup of patients with microembolic signals, in whom the signals persisted despite antithrombotic treatment, and who were at higher risk for ischaemic recurrence. Further studies including TCD monitoring before and after initiation of antithrombotic treatment are needed to resolve this issue.

We found a non-significant trend towards a higher proportion of potential arterial sources of embolism in patients with microembolic signals. The lack of significance may be due to a sample size effect, because previous studies have documented an association between microembolic signals and high grade carotid stenosis. ${ }^{4-6}$ Moreover, microembolic signals have also been found in symptomatic patients with aortic arch atheroma and no other apparent source of cerebral embolism. ${ }^{7}$ Both high grade carotid stenosis and thick aortic arch atheroma have been independently associated with increased risk of recurrence of stroke..$^{1-3}$ Therefore, although our finding suggests that microembolism may be a strong risk factor for early recurrence, the independent contribution of microembolism to the risk of early recurrence should be more precisely assessed on a larger sample.

In conclusion, in a small and selected sample, patients with recent cerebral ischaemia of presumed arterial origin and microembolism on TCD monitoring of the symptomatic middle cerebral artery were at high risk for early ischaemic recurrence.

We thank A de Falguerolles and G Tap (Laboratory of Statistics, Paul Sabatier University) for statistical advice, C Antolin, EM Ségui, E Boutonnet, M Matignon, and JM Caumont for their technical assistance, and E Sambres for her secretarial help.

1 European Carotid Surgery Trialists' Collaborative Group. MRC European carotid surgery trial: interim results for symptomatic patients with severe $(70 \%$ to $99 \%)$ or with mild ( $0 \%$ to $29 \%$ ) carotid stenosis. Lancet 1991;337:123543.

2 North American Symptomatic Carotid Endarterectomy Trial (NASCET) Collaborators. Beneficial effect of carotid endarterectomy in symptomatic patients with high-grade carotid stenosis. N Engl F Med 1991;325:445-53.

3 The French Study of Aortic Plaques in Stroke Group. Atherosclerotic disease of the aortic arch as a risk factor for recurrent ischemic stroke. N Engl f Med 1996;334:121621.

4 Spencer MP, Thomas GI, Nicholls SC, Sauvage LR. Detection of middle cerebral artery emboli during carotid endarterectomy using transcranial Doppler ultrasonography. Stroke 1990;21:415-23.

5 Siebler M, Sitzer M, Rose G, Benfeldt D, Steinmetz H. Silent cerebral embolism caused by neurologically symptomatic high-grade carotid stenosis: event rates before and after carotid endarterectomy. Brain 1993;116:1005-15.

6 Markus HS, Thomson ND, Brown MM. Asymptomatic cerebral embolic signals in symptomatic and asymptomatic carotid artery disease. Brain 1995;118:1005-11.

7 Valton L, Pavy le Traon A, Larrue V, Géraud G, Bès A. Microembolism in patients with recent cerebral ischemia and Cerebral Dynamics. Amsterdam: Elsevier, 1997 (in press).

8 Babikian VL, Hyde C, Pochay V, Winter MR. Clinical correlates of high-intensity transient signals detected on transcranial Doppler sonogaphy in patients with cerebrovascular disease. Stroke 1994;25:1570-3.

9 Sitzer M, Müller W, Siebler M, Hort W, Kniemeyer HW, Jäncke L, Steinmetz H. Plaque ulceration and lumen Jancke L, Steinmetz H. Plaque ulceration and lumen high-grade internal carotid artery stenosis. Stroke 1995;26: high-grade

10 Valton L, Larrue V, Arrué P, Géraud G, Bès A. Asymptomatic cerebral embolic signals in patients with carotid stenosis. Correlation with appearance of plaque ulceration on angiography. Stroke 1995;26:813-5.

11 North American Symptomatic Carotid Endarterectomy Trial (NASCET) Steering Commitee. North American symptomatic carotid surgery trial: methods, patient characsymptomatic carotid surgery trial: methods, patien
teristics, and progress. Stroke 1991;22:711-20.

12 Droste DW, Markus HS, Brown MM. The effect of alterations in ultrasound power, gain and sample volume on the appearance of emboli studied in a transcranial Doppler model. Cerebrovasc Dis 1994;4:152-6.

13 Markus HS. Importance of time window overlap in the detection and analysis of embolic signals. Stroke 1995;26: 2044-7.

14 Consensus Committee of the Ninth International Cerebral Hemodynamics Symposium. Basic identification criteria of Doppler microembolic signals. Stroke 1995;26:1123.

15 Scandinavian Stroke Study Group. Multicenter trial of hemodilution in ischemic stroke. Background and study protocol. Stroke 1985;16:885-90.

16 Siebler M, Nachtmann A, Sitzer M, Rose G, Kleinschmidt A, Rademacher J, Steinmetz H. Cerebral microembolism and the risk of ischemia in asymptomatic high-grade internal carotid artery stenosis. Stroke 1995;26:2184-6.

17 Nabavi DG, Georgiadis D, Mumme T, Schmid C, Mackay TG, Scheld HH, Ringelstein EB. Clinical relevance of intracranial microembolic signals in patients with left ventricular assist devices. A prospective study. Stroke 1996;27: 891-6.

18 TongDC, Albers GW. Transcranial Doppler-detected microemboli in patients with acute stroke. Stroke 1995;26: 
19 Müffelmann B, Sitzer M, Siebler M, Steinmetz H, Busse O. Detection of intracranial emboli in patients with acute cerebral ischemia [abstract]. If Neuroimaging 1995;5(supl 2):S67.

20 Koennecke HC, Mast H, Trocio S, Sacco RL, Ma W, Mohr JP, Kim P, Thomson JLP. Prevalence of microemboli in patients with acute cerebral ischemia [abstract]. Neurology 1996;46:A387.

21 Tegeler CH, Burke GL, Howard G, Knappertz VA, Mooney $\mathrm{MH}$, Myers LG. Prevalence and risk factors for highintensity transient signals in acute stroke [abstract]. Neurology 1996;46:A388.
22 Daffelshofer $M$, Ries S, Schminke U, Hennerici $M$. High-intensity transient signals in patients with cerebral ischemia. Stroke 1996;27:1844-9.

23 Sandercok P, Tangkanakul C. Very early prevention of stroke recurrence. Cerebrovasc Dis 1997;7(suppl1):10-5.

24 Markus HS, Droste D, Brown MM. Ultrasonic detection of cerebral emboli in carotid stenosis [letter; comment]. Lancet 1993;341:1603.

25 Siebler M, Nachtmann A, Sitzer M, Steinmetz H, Freund HJ. Anticoagulation and cerebral microemboli detection [letter]. Lancet 1994;344:555. 